McCutcheon, Mark A. "A Close Reading of Part 5 of Robert Kroetsch's 1977 Long Poem Seed Catalogue." The Explicator, vol. 75, no. 2, 2017, pp. 118-20. Taylor \& Francis Online, http://www.tandfonline.com/doi/full/10.1080/00144940.2017.1312258

Publisher's notice: Reprinted from The Explicator, with permission of Taylor \& Francis. (C) 2017 Taylor \& Francis Group, LLC.

Author's notice: Per Taylor \& Francis' "green" Open Access policy (http://www.sherpa.ac.uk/romeo/issn/0014-4940/), the Open Access version presented below is the post-print version (final, refereed, and copy-edited), not the publisher's version of record, which is available at http://www.tandfonline.com/doi/full/10.1080/00144940.2017.1312258.

\title{
A Close Reading of Part 5 of Robert Kroetsch's 1977 long poem SEED CATALOGUE
}

Mark A. McCutcheon

Athabasca University

Keywords: Poetry; Canada; Dada; poststructuralism

5

I planted some melons, just to see what would happen. Gophers ate everything.

I applied to the Government.

I wanted to become a postman, to deliver real words to real people.

There was no one to receive my application.

I don't give a damn if I do die do die do die do die do die do die do die do die do die do die do die do die do die do die do die do die do die do die do die do die do die do die do (Kroetsch 27)

Part 5 of Kroetsch's nine-part long poem Seed Catalogue, which part is quoted above in its entirety, develops both the agricultural conceit that structures the whole poem (which juxtaposes found excerpts from a seed catalogue with reflections on the question "How do you grow a poet? [29]) and the poet's play with literary tradition. The section is comprised of four stanzas that construct among them three distinct lyrical moments; what unifies these moments (and relates them to the poem as a whole) is their articulation of an 
absurdity in a tone oscillating, somewhat ambiguously, between humour and nihilism. The first moment depicts the persona's attempt to plant melons, only to be thwarted by hungry gophers who "ate everything" (27, line 2$)$. The second moment depicts the persona applying in futility to work at a post office where "there was no one." The third moment turns the last two words of the line "I don't give a damn if I do die" into a fourline chant that attains both singsong and deconstructive qualities.

The first of these three moments refers back to the farming and gardening motifs that open the poem and furnish its overall structure and recurring imagery. Significant, however, is the persona's failure in agriculture, as his attempt to plant melons is thwarted by hungry gophers, which are one of the most iconic and ubiquitous animals to be found on the Canadian prairies (as memorialized, for example, by the adorably bizarre Gopher Hole Museum in Torrington, Alberta). Gophers are also, of course, a nuisance to farmers; this passage in the poem signals the persona's difference and even alienation from his family's farming roots, not only in the failure of his attempt to plant melons, but also in the reason he gives for trying in the first place: "just to see what would / happen."

This rationale is itself absurd, an admission of arbitrariness, that extends into the second moment, the persona's similarly unsuccessful attempt "to become a postman." As work "to deliver real words / to real people," the work of the postal carrier serves as a figure or analogy of the work of the poet, the development of which becomes the question asked in the next section $(29$, line 9$)$. But here too the persona fails: "There was no one to receive / my application" (27, lines $7-8)$. These lines might suggest literally that the post office where the persona applies is under-staffed, closed, or nonexistent, but the generalized wording — "no one"- - suggests a larger, existential failure, a national or even metaphysical emptiness (of the kind that informed major theories of Canadian literature that were contemporaries of Kroetsch's mid-1970s poem, such as those of Northrop Frye and Margaret Atwood).

This passage also gestures sideways to the poststructuralist (and more specifically deconstructionist) theory with which Kroetsch's poetics became associated, in its reference to the "postman" and to the "deliver[y of] real words"; these linesintentionally or otherwise - allude to a cryptic claim that encapsulates French poststructuralist theory, as argued between Jacques Lacan, who claimed that "a letter always arrives at its destination" (72), and Jacques Derrida, who countered that "a letter can always not arrive at its destination" (65). The passage thus both conjures the assumptions of presence, authenticity, and meaning as transmission that informed structuralist theories of communication - and, like poststructuralism, critiques these assumptions: the duplication of "real" creates an emphasis that immediately feels inordinate, suspect, in its very doubling; and the subsequent observation of "no one" confirms that feeling.

The third moment thus carries forward the absurdity and nihilism of the first two moments, and in addition foreshadows the poem's eighth part. Extending the slang interjection "I don't give a damn if I do die" into a long, repetitious chant, this third moment quickly descends into nonsense word play - a long repetition of "do die do die" - that reminds the reader of Dada, the aesthetics of absurdity, nonsense, pastiche, provocation, and revolt that arose in Europe, via the work of Tristan Tzara and others, in the bleak, bewildering aftermath of World War One. Dada poetry experimented extensively with sound and nonsense, and this moment in Kroetsch's poem references 
that tradition - almost eponymously. The repeating "do die" echoes the name of Tzara's movement, and Tzara's own practice of invoking the name "Dada" repeatedly, reducing the signifier to sound and fury, signifying nothing. "DADA DOES NOT MEAN ANYTHING," declares Tzara's Dada Manifesto of 1818 (4), and its closing paragraph, "Dadaist disgust," repeats "Dada" fourteen times: "DADA DADA DADA; - the roar of contorted pains, the interweaving of contraries..." (13). The repetition of "die" and the evocation of Dadaist aesthetics, which was an outraged response to globalized, industrialized warfare, both foreshadow the poem's eighth section, which describes the ironic and tragic first visit of a descendant of the persona's immigrant family back to their European homeland - on a mission to bomb that homeland as part of Allied forces' attack on Germany.

This "nonsense" passage also represents word play that spins off associated suggestions and meanings. It begins to resemble song, especially in how the poet ends the refrain not on "die" but on "do." Specifically, the alternating two-syllable repetition of these lines assumes the musical quality of a horse trot or the sort of two-note rhythm guitar heard in country classics like Johnny Cash's "Walk the Line." Furthermore, this passage evokes the commonplace phrase "do or die," as economic and pragmatic an expression of the prairie pioneer ethos as can be found anywhere. Of course, in the context of the sentiment that opens the repetition, these alternating words also summarize, just as tersely, the only options that the persona feels are available to him, as a prairie youth who wants to pursue the writing of poetry. To "do" it or to "die" trying: that is two questions.

In addition, the alliterative repetition of two very short words, encapsulating this colonial survivalist ethos, and varying by only one syllable, creates a visual and sonic flatness and monotony that both evoke and also perhaps stereotype the flat expanse of the landscape of Heisler, in eastern Alberta, on the vast Canadian prairie where the poem is set, and where Kroetsch's complicated poetics take both root and routes. What better place to grow the "long poem" in Canada?

\section{Acknowledgment}

The author is grateful to Turnstone Press for granting permission to reprint part 5 of Robert Kroetsch's Seed Catalogue in this article.

\section{Works Cited}

Derrida, Jacques. "The Purveyor of Truth." Trans. Willis Domingo, James Hulbert, Moshe Ron, and M.-R. L. Yale French Studies 52 (1975): 31-113. Web.

Kroetsch, Robert. Seed Catalogue. Winnipeg: Turnstone P, 1977. Print.

Lacan, Jacques. "Seminar on "The Purloined Letter." Trans. Jeffrey Mehlman. Yale French Studies 48 (1972): 39-72. Web.

Tzara, Tristan. Seven Dada Manifestoes and Lampisteries (1963). Trans. Barbara Wright. London: John Calder, 1977. Print. 